\title{
ANALYSIS OF TECHNIQUE FOR ORDER PREFERENCE BY SIMILARITY TO IDEAL SOLUTION IN DETECTING COFFEE BEAN QUALITY
}

\author{
Lavenia Ulandari \\ Program Study Computer System, Faculty Science and Technology, Universitas \\ Pembangunan Panca Budi, Medan, North Sumatera, Indonesia
}

\begin{abstract}
Decision support system is a science that can be applied in various fields to be able to assist decision makers in supporting not as absolute decision makers. As a decision has a reliable method in each case or data processed. Like TOPSIS is a very good method in helping decision making that is implemented well in a system. In this paper, detection is carried out to help support decisions on quality coffee beans. Coffee is a typical drink from various countries. Coffee produced from quality coffee beans and coffee farm fields. So that the final result of this paper is to get the best value for detecting quality coffee beans based on 3 coffee bean farming fields, in which the three fields are labeled with A1 and the optimal criterion value is 0.61 .
\end{abstract}

Keyword: DSS, TOPSIS, Coffee.

\section{INTRODUCTION}

In this era of computerization, the human need for information has spurred the rapid development of technology in the field of information and technology [1][2]. Increasing technology is supported by adequate facilities and infrastructure, proving that now information has become a basic need in human life [3]. Information systems and information technology serve as support for making the right decisions based on available information[4].

One of the information needed is data or information that is right on target regarding the quality and quantity in detecting the best coffee beans [5][6]. Knowledge about coffee that can be developed in a desktop application, which can make it easier for people who want to know more about coffee beans and detect the best coffee beans for consumption [7].

Indonesia is one of the world's coffee producing countries, along with countries such as Brazil, Colombia and Vietnam [8]. Most of the coffee plants in Indonesia (90\%) are cultivated by farmers with a relatively low level of productivity, namely $500 \mathrm{~kg} / \mathrm{ha}$ [9]. Meanwhile, private and state plantations are able to achieve a productivity of $1000 \mathrm{~kg} / \mathrm{ha}$ [10]. Seen from the aspect of the quality/quality of the coffee produced, it is still quite apprehensive, where the majority are still in the Medium grade (Grades 3 and 4). With such quality, the selling price of coffee farmers in the market is certainly still low and this is what causes the income level of coffee farmers to also be low [11].

Since 1978 through the Decree of the Minister of Trade No. 108/Kp/VII/78 On July 1, 1978 the standard of coffee bean quality used was the TRIASE SYSTEM [12]. However, 
from October 1, 1983 until now, to determine the quality of coffee, Indonesia uses the Defects Value System according to the decision of the ICO (International Coffee Organization). In a defective system, the more defects there are, the lower the coffee quality and vice versa. For this reason, in this paper, detecting quality coffee beans is one of the efforts to provide information about the best coffee beans for consumption.

\section{RESEARCH METHODOLOGY}

Analyze and collect all the requirements needed to solve the problems that will be solved by using a decision support system to detect the best coffee beans. For this reason, it is necessary to determine which input and output variables will be processed into the TOPSIS method (Technique for order preference by similarity to ideal solution). The test carried out is method testing (Method Testing) using the TOPSIS method (TOPSIS method is a framework for making decisions effectively. TOPSIS method testing (Technique for order preference by similarity to ideal solution) focuses on visible user actions and users can recognize the output. of the system, this test runs the system in an active environment using the correct data. At this stage the test is only an administrator who has full access rights to the system [13].

Coffee beans are seeds that come from coffee cherries that are clustered in stalks, with red skin when ripe. Beneath the fruit flesh layer (mesocarp), there are two seeds with flat sides facing each other, each covered by a thin layer (endocarp). When the coffee is ripe, a thin mucus surrounds the endocarp. Beneath the endocarp, the coffee bean is again covered with another thin membrane, a fine silvery layer (seed coat). Each coffee fruit contains two coffee beans and if there is only one piece that is round then it is known as a peaberry. To determine the maximum detection of coffee beans, a technique or method is needed that can assist in choosing the best coffee beans to be consumed. In the discussion the authors conducted interviews with coffee farmers to obtain data to be processed [14].

The discussion using the TOPSIS method (Technique for order preference by similarity to ideal solution) for the case consists of several steps, such as the weight of the criteria assessment, alternative assessment and calculation of the final score. This method is widely used to complete practical decision making. This is because the concept is simple and easy to understand, computationally efficient, and has the ability to measure the relative performance of decision alternatives [15].

\section{TOPSIS procedure}

TOPSIS method has several procedures in decision makers. The procedure is as follows [16]:

1. Calculate the separation measure.

2. Determine the distance between the values of each alternative and the positive and negative ideal solution matrices.

3. Determine the preference value for each alternative. 
4. Decision matrix $\mathrm{D}$ refers to $\mathrm{m}$ alternatives that will be evaluated based on $\mathrm{n}$ criteria defined as follows:

$D=\left[\begin{array}{ccc}x 11 & \cdots & x 1 n \\ \vdots & \ddots & \vdots \\ x m 1 & \cdots & x m n\end{array}\right]$

(1)

\section{TOPSIS solution steps}

The steps in solving problems with the TOPSIS method will be explained as follows [17]:

1. Build a normalized decision matrix. The formula for determining the normalized matrix is as follows:

Table 1 Normalized Matrix

\begin{tabular}{|l|c|c|c|c|c|c|}
\hline & \multicolumn{3}{|c|}{ Criteria } \\
\hline A1 & $\frac{x_{11}}{\sqrt{x_{11}^{2}+x_{21}^{2}}}$ & $\frac{x_{12}}{\sqrt{x_{12}^{2}+x_{22}^{2}}}$ & $\frac{x_{13}}{\sqrt{x_{13}^{2}+x_{23}^{2}}}$ & $\frac{x_{14}}{\sqrt{x_{14}^{2}+x_{24}^{2}}}$ & $\frac{x_{15}}{\sqrt{x_{15}^{2}+x_{25}^{2}}}$ & $\frac{x_{16}}{\sqrt{x_{16}^{2}+x_{26}^{2}}+}$ \\
\hline A2 & $\frac{x_{21}}{\sqrt{x_{11}^{2}+x_{21}^{2}}}$ & $\frac{x_{22}}{\sqrt{x_{12}^{2}+x_{22}^{2}}+}$ & $\frac{x_{23}}{\sqrt{x_{13}^{2}+x_{23}^{2}}}$ & $\frac{x_{24}}{\sqrt{x_{14}^{2}+x_{24}^{2}}}$ & $\frac{x_{25}}{\sqrt{x_{15}^{2}+x_{25}^{2}}}$ & $\frac{x_{26}}{\sqrt{x_{16}^{2}+x_{26}^{2}}+}$ \\
\hline A3 & $\frac{x_{31}}{\sqrt{x_{11}^{2}+x_{21}^{2}}}$ & $\frac{x_{32}}{\sqrt{x_{12}^{2}+x_{22}^{2}}+}$ & $\frac{x_{33}}{\sqrt{x_{13}^{2}+x_{23}^{2}}}$ & $\frac{x_{34}}{\sqrt{x_{14}^{2}+x_{24}^{2}}}$ & $\frac{x_{35}}{\sqrt{x_{15}^{2}+x_{25}^{2}}}$ & $\frac{x_{36}}{\sqrt{x_{16}^{2}+x_{26}^{2}}+}$ \\
\hline
\end{tabular}

2. Build a weighted normalized decision matrix. The next step is to calculate the weighted normalization matrix with the following formula:

Table 2 Weighted Normalized Matrix

\begin{tabular}{|c|c|c|c|c|c|c|c|}
\hline No & Alternativ & \multicolumn{6}{|c|}{ Criteria } \\
\hline 1 & A1 & $w_{1} \cdot r_{11}$ & $w_{2} \cdot r_{12}$ & $w_{3} \cdot r_{13}$ & $w_{4} \cdot r_{14}$ & $w_{5} \cdot r_{15}$ & $w_{6} \cdot r_{16}$ \\
\hline 2 & $\mathrm{~A} 2$ & $w_{1} \cdot r_{21}$ & $w_{2} \cdot r_{22}$ & $w_{3} \cdot r_{13}$ & $w_{4} \cdot r_{24}$ & $w_{5} \cdot r_{25}$ & $w_{6} \cdot r_{26}$ \\
\hline 3 & A3 & $w_{1} \cdot r_{31}$ & $w_{2} \cdot r_{32}$ & $w_{3} \cdot r_{13}$ & $w_{4} \cdot r_{24}$ & $w_{5} \cdot r_{35}$ & $w_{6} \cdot r_{36}$ \\
\hline
\end{tabular}

3. Determine the ideal solution and the negative ideal solution. The ideal solution is denoted $\mathrm{A}+$, while the negative ideal solution is denoted $\mathrm{A}-$. the formula is as follows:

$$
A^{+}=\left\{\left(\max V_{i j} \mid j \in j\right),\left(\min V_{i j} \mid j \in j^{\prime}\right), i=1,2,3, \ldots, m\right\}=\left\{v_{1}^{+}, v_{2}^{+}, \ldots, v_{n}^{+}\right\}
$$


$A^{-}=\left\{\left(\min V_{i j} \mid j \in j\right),\left(\max V_{i j} \mid j \in j^{\prime}\right), i=1,2,3, \ldots, m\right\}=\left\{v_{1}^{-}, v_{2}^{-}, \ldots, v_{n}^{-}\right\}$

4. Calculating separation. $\mathrm{Si}+$ is the (in Euclidean view) alternative distance from the positive and negative ideal solutions defined as follows:

$$
s^{+}=\sqrt{\sum_{j=1}^{n}\left(V_{i j}-V_{j}^{+}\right)^{2}}
$$

$$
s^{-}=\sqrt{\sum_{j=1}^{n}\left(V_{i j}-V_{j}^{-}\right)^{2}}
$$

5. Calculating the relative closeness to the ideal solution. This step is a decision-making step using TOPSIS as for the formula as follows:

$$
C_{i=\frac{s_{i}^{-}}{s_{i}^{-}+s_{i}^{+}}}
$$

So after the steps above are built, the next step is to rank each $\mathrm{Ci}$ value.

\section{RESULT AND DISCUSSION}

Coffee beans are seeds that come from coffee cherries that are clustered in stalks, with red skin when ripe. Beneath the fruit flesh layer (mesocarp), there are two seeds with flat sides facing each other, each covered by a thin layer (endocarp). When the coffee is ripe, a thin mucus surrounds the endocarp. Beneath the endocarp, the coffee bean is again covered with another thin membrane, a fine silvery layer (seed coat). Each coffee fruit contains two coffee beans and if there is only one piece that is round then it is known as a peaberry.

To determine the maximum detection of coffee beans, a technique or method is needed that can assist in detecting which coffee beans are best consumed. In the discussion the authors conducted interviews with coffee farmers to obtain data to be processed. In the research the criteria used to determine the best coffee beans used as inputs are spacing, shade trees, soil type, SUPERNASA fertilizer application, coffee tree pests, coffee bean size, coffee bean color and coffee bean odor. The model for the description of the criteria is as follows: 
Tabel 3 Criteria

\begin{tabular}{|l|l|l|}
\hline No & Criteria & Information \\
\hline 1. & $\mathrm{x} 1$ & Planting Distance $(\mathrm{m})$ \\
\hline 2. & $\mathrm{x} 2$ & Protective tree \\
\hline 3. & $\mathrm{x} 3$ & Type of soil \\
\hline 4. & $\mathrm{x} 4$ & $\begin{array}{l}\text { SUPERNASA Organic } \\
\text { Fertilizer Provision }\end{array}$ \\
\hline 5. & $\mathrm{x} 5$ & Tree Pest \\
\hline 6. & $\mathrm{x} 6$ & Coffee Bean Size \\
\hline 7. & $\mathrm{x} 7$ & Coffee Bean Color \\
\hline 8. & $\mathrm{x} 8$ & Coffee Bean Smell \\
\hline
\end{tabular}

The discussion using the TOPSIS method (Technique for order preference by similarity to ideal solution) for the case consists of several steps, such as the weight of the criteria assessment, alternative assessment and calculation of the final score. The determination of the weight of the assessment has been carried out based on the criteria that have been determined based on the results of the study, but this can be carried out in the future according to the demands of the needs. That the system in the assessment process refers to the fulfillment of predetermined criteria and refers to several cases that have occurred, so that it really has a good benchmark. The evaluation criteria are as follows:

\section{Planting Distance}

Spacing is the criterion used for the assessment of the alternatives under consideration. The spacing variable consists of 4 (four) data, namely smaller than $2 \mathrm{~m}$ x $2 \mathrm{~m}, 2 \mathrm{~m} \times 2 \mathrm{~m}, 2.5 \mathrm{~m} \times 2.5 \mathrm{~m}$ and more than or equal to $2.75 \mathrm{~m} \times 2.75 \mathrm{~m}$. So that the data is given the weights shown in table 4 below.

Table 4. Spacing

\begin{tabular}{|c|c|}
\hline Data & Value \\
\hline$<2 \mathrm{~m} \times 2 \mathrm{~m}$ & 1 \\
\hline $2 \mathrm{~m} \times 2 \mathrm{~m}$ & 2 \\
\hline $2,5 \mathrm{~m} \times 2,5 \mathrm{~m}$ & 3 \\
\hline$>=2,75 \mathrm{~m} \times 2,75 \mathrm{~m}$ & 4 \\
\hline
\end{tabular}


2. Protective Tree

The shade tree is the criterion used for the assessment of the alternatives under consideration. The protective tree variable consists of 2 (two) data, namely none and present. So that the data is given a weight as shown in table 4.3 below.

Table 5. Protective Trees

\begin{tabular}{|c|c|}
\hline Data & Value \\
\hline No & 1 \\
\hline Yes & 2 \\
\hline
\end{tabular}

3. Soil Type

Soil type is the criterion used for the assessment of the alternatives under consideration. The soil type variable consists of 3 (three) data, namely dry, moist and not dry and not moist. So that from the data given the weights shown in table 6 below.

Table 6. Soil Types

\begin{tabular}{|c|c|}
\hline Data & Value \\
\hline Dry & 1 \\
\hline Moist & 2 \\
\hline Not Dry and Moist & 3 \\
\hline
\end{tabular}

4. SUPERNASA Organic Fertilizer Provision

SUPERNASA organic fertilizer is the criteria used for the assessment of the alternatives that are considered. The SUPERNASA organic fertilizer variable consists of 4 (four) data, namely Never, Irregular, between 2 to 3 months and between 4 to 6 months. So that the data is given a weight as shown in table 7 below.

Table 7 SUPERNASA Organic Fertilizer

\begin{tabular}{|c|c|}
\hline Data & Value \\
\hline Never & 1 \\
\hline Irregular & 2 \\
\hline Between 2 to 3 months & 3 \\
\hline Between 4 to 6 months & 4 \\
\hline
\end{tabular}


5. Coffee Tree Pests

Coffee tree pests are the criteria used for the assessment of the alternatives under consideration. The coffee tree pest variable consists of 2 (two) data, namely absent and present. So that the data is given a weight as shown in table 8 below.

Table 8. Pests of coffee trees

\begin{tabular}{|c|c|}
\hline Data & Value \\
\hline No & 1 \\
\hline Yes & 2 \\
\hline
\end{tabular}

6. Coffee Bean Size

The size of the coffee bean is the criterion used for the assessment of the alternatives under consideration. The coffee bean size variable consists of 4 (four) data, namely very small, small, medium and large. So that the data is given the weights shown in table 9 below.

Table 9. Coffee Bean Size

\begin{tabular}{|c|c|}
\hline Data & Value \\
\hline Very small & 1 \\
\hline Small & 2 \\
\hline Medium & 3 \\
\hline Big & 4 \\
\hline
\end{tabular}

7. Coffee Bean Color

Coffee Bean Color is the criterion used for the assessment of the alternatives under consideration. The coffee bean color variable consists of 4 (four) data, namely brownish, brownish green, fresh green and bluish green. So that the data is given a weight as shown in table 10 below.

Table 10. Colors of Coffee Beans

\begin{tabular}{|c|c|}
\hline Data & Value \\
\hline Brown & 1 \\
\hline Brownish Green & 2 \\
\hline Fresh Green & 3 \\
\hline Blue Green & 4 \\
\hline
\end{tabular}


8. The smell of coffee beans

The smell of coffee beans is a criterion used to assess the alternatives under consideration. The seed odor variable consists of 2 (two) data, namely odorless and odorless. So that the data is given a weight as shown in table 11 below.

Table 11. Seed Odor

\begin{tabular}{|c|c|}
\hline Data & Value \\
\hline Yes & 1 \\
\hline No & 2 \\
\hline
\end{tabular}

Determining the ranking of each alternative, then first determine the importance of each criterion $(\mathrm{Wj})$. The determination of the importance weight of each criterion $(\mathrm{Wj})$ is formed in table 12 below:

Table 12 Determination of the Weight of Interest from the Criteria $(\mathrm{Wj})$

\begin{tabular}{|l|c|}
\hline \multicolumn{1}{|c|}{ Criteria } & Value \\
\hline Planting Distance (m) & 4 \\
\hline Protective tree & 3 \\
\hline Type of soil & 2 \\
\hline $\begin{array}{l}\text { SUPERNASA Organic } \\
\text { Fertilizer Provision }\end{array}$ & 2 \\
\hline Tree Pest & 2 \\
\hline Coffee Bean Size & 2 \\
\hline Coffee Bean Color & 2 \\
\hline Coffee Bean Smell & \\
\hline
\end{tabular}


From the table above, the weight value $(\mathrm{Wj})$ is obtained with data $\mathrm{W}=[4,3,3,2,2,2$, 2, 2 ]. From the criteria data that has been started in table 4.1 to table 4.7 above, the next step is to determine the suitability rating as shown in table 13 below:

Table 13. Preliminary Data from each alternative

\begin{tabular}{|l|l|l|l|l|l|l|l|l|l|}
\hline No & Alternative & \multicolumn{8}{|c|}{ Criteria } \\
\hline 1 & Farm 1 & 3 & 2 & 3 & 3 & 2 & 4 & 4 & 1 \\
\hline 2 & Farm 2 & 2 & 2 & 3 & 2 & 1 & 4 & 4 & 2 \\
\hline 3 & Farm 3 & 4 & 1 & 3 & 4 & 2 & 1 & 4 & 1 \\
\hline
\end{tabular}

After obtaining initial data from each alternative, the calculation of the TOPSIS method begins by building a decision matrix. In the decision matrix, the matrix column states the attributes, namely the existing criteria, while the matrix rows state the alternative, namely the possible coffee bean fields. The decision matrix refers to $\mathrm{m}$ alternatives that will be evaluated based on $n$ criteria. The decision matrix can be seen in the following table:

Table 14. Decision Matrix

\begin{tabular}{|l|l|l|l|l|l|l|l|l|l|}
\hline No & Alternative & \multicolumn{7}{|c|}{ Criteria } \\
\hline 1 & A1 & $\mathrm{X}_{11}$ & $\mathrm{X}_{12}$ & $\mathrm{X}_{13}$ & $\mathrm{X}_{14}$ & $\mathrm{X}_{15}$ & $\mathrm{X}_{16}$ & $\mathrm{X}_{17}$ & $\mathrm{X}_{18}$ \\
\hline 2 & $\mathrm{~A} 2$ & $\mathrm{X}_{21}$ & $\mathrm{X}_{22}$ & $\mathrm{X}_{23}$ & $\mathrm{X}_{24}$ & $\mathrm{X}_{25}$ & $\mathrm{X}_{26}$ & $\mathrm{X}_{27}$ & $\mathrm{X}_{28}$ \\
\hline 3 & $\mathrm{~A} 3$ & $\mathrm{X}_{31}$ & $\mathrm{X}_{32}$ & $\mathrm{X}_{33}$ & $\mathrm{X}_{34}$ & $\mathrm{X}_{35}$ & $\mathrm{X}_{36}$ & $\mathrm{X}_{37}$ & $\mathrm{X}_{38}$ \\
\hline
\end{tabular}

In the table above, the formula $\mathrm{x} 11, \ldots, \mathrm{x} 38$ states the performance of the alternative with the criterion reference being the criterion score data for each alternative. Xij is the performance of the ith alternative for the jth criterion, $\operatorname{Ai}(i=1,2,3, \ldots, n)$ is the possible alternatives, $x j(j=1,2,3, \ldots, n)$ is the criterion where performance has been measured. In this study the value of $\mathrm{j}=1$ for spacing, $\mathrm{j}=2$ for shade trees, $\mathrm{j}=3$ for soil types, $\mathrm{j}=4$ for SUPERNASA organic fertilizer application, $j=5$ for tree pests, $j=6$ for coffee bean size, $J$ $=7$ for the color of the coffee beans, and $\mathrm{J}=8$ for the smell of the coffee beans. The results of the decision matrix formed from the alternative initial data table can be presented in the following table 15:

Table 15 Result of Decision Matrix

\begin{tabular}{|l|l|l|l|l|l|l|l|l|l|}
\hline No & Alternative & \multicolumn{8}{|c|}{ Criteria } \\
\hline 1 & Farm 1 & 3 & 2 & 3 & 3 & 2 & 4 & 4 & 1 \\
\hline 2 & Farm 2 & 2 & 2 & 3 & 2 & 1 & 4 & 4 & 2 \\
\hline 3 & Farm 3 & 4 & 1 & 3 & 4 & 2 & 1 & 4 & 1 \\
\hline
\end{tabular}

After the decision matrix is made, the next step is to make a normalized decision matrix $\mathrm{R}$ whose function is to reduce the range of data, with the aim of simplifying TOPSIS calculations and saving memory usage. So that the normalized decision matrix is listed in the following table 16 : 
Table 16. Normalized Matrix Results

\begin{tabular}{|l|l|l|l|l|}
\hline A1 & $\frac{3}{\sqrt{3^{2}+2^{2}+4}} \sqrt{\sqrt{2^{2}+2^{2}+1^{2}}}$ & $\frac{2}{\sqrt{3^{2}+3^{2}+3^{2}}}$ & $\frac{3}{\sqrt{3^{2}+2^{2}+4^{2}}}$ \\
\hline A2 & $\frac{2}{\sqrt{3^{2}+2^{2}+4}}$ & $\frac{2}{\sqrt{2^{2}+2^{2}+1^{2}}}$ & $\frac{3}{\sqrt{3^{2}+3^{2}+3^{2}}}$ & $\frac{2}{\sqrt{3^{2}+2^{2}+4^{2}}}$ \\
\hline A3 & $\frac{4}{\sqrt{3^{2}+2^{2}+4}}$ & $\frac{1}{\sqrt{2^{2}+2^{2}+1^{2}}}$ & $\frac{3}{\sqrt{3^{2}+3^{2}+3^{2}}}$ & $\frac{4}{\sqrt{3^{2}+2^{2}+4^{2}}}$ \\
\hline A1 & $\frac{2}{\sqrt{2^{2}+1^{2}+2}}$ & $\frac{4}{\sqrt{4^{2}+4^{2}+1^{2}}}$ & $\frac{4}{\sqrt{4^{2}+4^{2}+4^{2}+1^{2}}}$ & $\frac{4}{\sqrt{1^{2}+2^{2}+1^{2}}}$ \\
\hline A2 & $\frac{1}{\sqrt{2^{2}+1^{2}+2}}$ & $\frac{4}{\sqrt{4^{2}+4^{2}+1^{2}}}$ & $\frac{4}{\sqrt{4^{2}+4^{2}+4^{2}}}$ & $\frac{1}{\sqrt{1^{2}+2^{2}+1^{2}}}$ \\
\hline A3 & $\frac{2}{\sqrt{2^{2}+1^{2}+2}}$ & $\frac{1}{\sqrt{4^{2}+4^{2}+1^{2}}}$ & $\sqrt{4^{2}+4^{2}+4^{2}}$ & $\sqrt{1^{2}}$ \\
\hline
\end{tabular}

So, from the above function, the calculation is as follows:

Table 17 Normalized Matrix Calculation Results

\begin{tabular}{|l|l|l|l|l|l|l|l|l|l|}
\hline No & $\begin{array}{l}\text { Alternativ } \\
\text { e }\end{array}$ & \multicolumn{7}{|c|}{ Kriteria } \\
\hline 1 & A1 & 0.56 & 0.67 & 0.58 & 0.56 & 0.67 & 0.70 & 0.58 & 0.41 \\
\hline 2 & A2 & 0.37 & 0.67 & 0.58 & 0.37 & 0.33 & 0.70 & 0.58 & 0.82 \\
\hline 3 & A3 & 0.74 & 0.33 & 0.58 & 0.74 & 0.67 & 0.17 & 0.58 & 0.41 \\
\hline
\end{tabular}

After the decision matrix has been normalized, the next step is to create a V-weighted normalized matrix as follows:

Table 18. Results of the Weighted Normalized Matrix

\begin{tabular}{|l|l|l|l|l|l|l|l|l|l|}
\hline No & $\begin{array}{l}\text { Alternativ } \\
\text { e }\end{array}$ & \multicolumn{7}{|c|}{ Criteria } \\
\hline 1 & A1 & 2.23 & 2.00 & 1.15 & 1.11 & 1.33 & 1.39 & 1.15 & 0.82 \\
\hline 2 & $\mathrm{~A} 2$ & 1.49 & 2.00 & 1.15 & 0.74 & 0.67 & 1.39 & 1.15 & 1.63 \\
\hline 3 & $\mathrm{~A} 3$ & 2.97 & 1.00 & 1.15 & 1.49 & 1.33 & 0.35 & 1.15 & 0.82 \\
\hline
\end{tabular}


After performing the above steps, the next step is to determine the matrix of a positive ideal solution $(\mathrm{A}+)$ and a negative ideal solution $(\mathrm{A}-)$. The formula is as follows:

$$
\begin{aligned}
& A^{+}=\left\{\left(\max V_{i j} \mid j \in j\right),\left(\min V_{i j} \mid j \in j^{\prime}\right), i=1,2,3, \ldots, m\right\}=\left\{v_{1}^{+}, v_{2}^{+}, \ldots, v_{n}^{+}\right\} \\
& A^{-}=\left\{\left(\min V_{i j} \mid j \in j\right),\left(\max V_{i j} \mid j \in j^{\prime}\right), i=1,2,3, \ldots, m\right\}=\left\{v_{1}^{-}, v_{2}^{-}, \ldots, v_{n}^{-}\right\}
\end{aligned}
$$

So that the max and min values of each criterion are obtained from table 19 as follows:

Table 19 Max and Min Results

\begin{tabular}{|l|l|l|l|l|l|l|l|l|l|}
\hline No & $\begin{array}{l}\text { Alternativ } \\
\mathrm{e}\end{array}$ & \multicolumn{7}{|c|}{ Criteria } \\
\hline 1 & $\mathrm{~A}^{+}$ & 2.97 & 2.00 & 1.15 & 1.49 & 1.33 & 1.39 & 1.15 & 1.63 \\
\hline 2 & $\mathrm{~A}^{-}$ & 1.49 & 1.00 & 1.15 & 0.74 & 0.67 & 0.35 & 1.15 & 0.82 \\
\hline
\end{tabular}

So that it can be calculated from the distance of the positive (S+) and negative (S-) ideal solutions from each alternative determined and the $\mathrm{S}+$ and $\mathrm{S}$ - values obtained from each alternative are as follows: 
Tabel $20 \mathrm{~S}^{+}$and $\mathrm{S}^{-}$Value

\begin{tabular}{|c|c|c|}
\hline No & $\begin{array}{l}\text { Alternativ } \\
\mathrm{e}\end{array}$ & Kriteria \\
\hline 1 & $\mathrm{~A}^{+} 1$ & 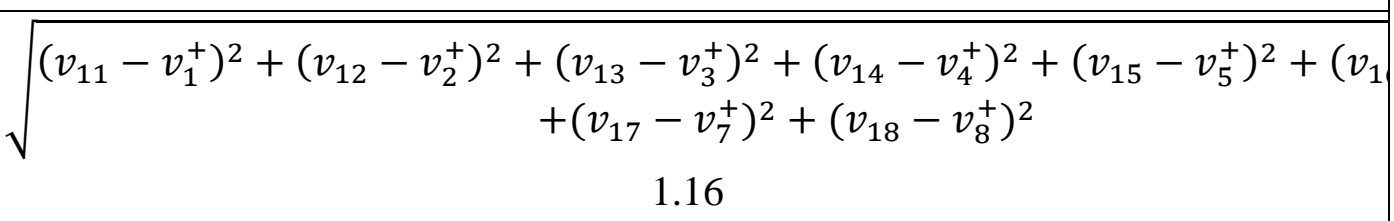 \\
\hline 2 & $\mathrm{~A}^{+} 2$ & $\sqrt{\begin{array}{c}\left(v_{21}-v_{1}^{+}\right)^{2}+\left(v_{22}-v_{2}^{+}\right)^{2}+\left(v_{23}-v_{3}^{+}\right)^{2}+\left(v_{24}-v_{4}^{+}\right)^{2}+\left(v_{25}-v_{5}^{+}\right)^{2}+\left(v_{2}\right. \\
+\left(v_{27}-v_{7}^{+}\right)^{2}+\left(v_{28}-v_{8}^{+}\right)^{2} \\
1.79\end{array}}$ \\
\hline 3 & $\mathrm{~A}^{+} 3$ & $\sqrt{\begin{array}{c}\left(v_{31}-v_{1}^{+}\right)^{2}+\left(v_{32}-v_{2}^{+}\right)^{2}+\left(v_{33}-v_{3}^{+}\right)^{2}+\left(v_{34}-v_{4}^{+}\right)^{2}+\left(v_{35}-v_{5}^{+}\right)^{2}+\left(v_{3}\right. \\
+\left(v_{37}-v_{7}^{+}\right)^{2}+\left(v_{38}-v_{8}^{+}\right)^{2} \\
1,66\end{array}}$ \\
\hline 4 & $\mathrm{~A}^{-1} 1$ & $\sqrt{\begin{array}{c}\left(v_{11}-v_{1}^{-}\right)^{2}+\left(v_{12}-v_{2}^{-}\right)^{2}+\left(v_{13}-v_{3}^{-}\right)^{2}+\left(v_{14}-v_{4}^{-}\right)^{2}+\left(v_{15}-v_{5}^{-}\right)^{2}+\left(v_{1}\right. \\
+\left(v_{17}-v_{7}^{-}\right)^{2}+\left(v_{18}-v_{8}^{-}\right)^{2} \\
1,80\end{array}}$ \\
\hline 5 & $\mathrm{~A}^{-2} 2$ & 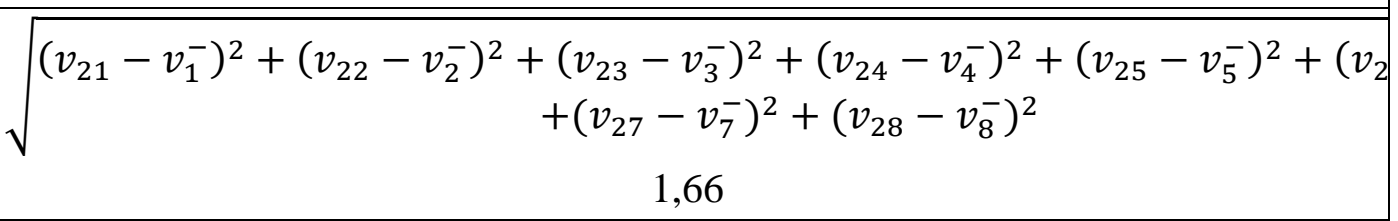 \\
\hline 6 & $A-3$ & $\begin{array}{c}\sqrt{\left(v_{31}-v_{1}^{-}\right)^{2}+\left(v_{32}-v_{2}^{-}\right)^{2}+\left(v_{33}-v_{3}^{-}\right)^{2}+\left(v_{34}-v_{4}^{-}\right)^{2}+\left(v_{35}-v_{5}^{-}\right)^{2}+\left(v_{3}\right.} \\
+\left(v_{37}-v_{7}^{-}\right)^{2}+\left(v_{38}-v_{8}^{-}\right)^{2} \\
1,79\end{array}$ \\
\hline
\end{tabular}

So that the value of each alternative can be sorted to find out which coffee fields have the best coffee beans so that they are healthy for consumption.

Table 21. Decision Results

\begin{tabular}{|l|l|c|}
\hline No & $\begin{array}{l}\text { Alternativ } \\
\text { e }\end{array}$ & Criteria \\
\hline 1 & A1 & 0,61 \\
\hline 2 & A3 & 0,52 \\
\hline 3 & A2 & 0,48 \\
\hline
\end{tabular}

So that it has been obtained to determine the best coffee beans using the TOPSIS method in the study, namely the best alternative A1 where A1 is the number 1 coffee field of the 2 coffee fields analyzed. 


\section{CONCLUSSION}

The TOPSIS method, which is a decision support system method in solving various multicriteria decision-making problems, can also be used in a coffee bean detection decision support system. The criteria needed to detect coffee beans are moisture content, dirt, size, color, odor and pests. In this study, in detecting coffee beans using the TOPSIS method, it was concluded that field 1 is a field that has detected coffee beans so that the field is the field that has the best coffee beans. The application of this coffee bean detection decision support system can be used as a supporting tool for coffee bean farmers while remaining based on a decision support system and not to replace assessment and not stressed to make or make decisions

\section{REFERENCES}

[1] A. M. F, Fauzi; Al-Khowarizmi, "The e-Business Community Model is Used to Improve Communication Between Businesses by Utilizing," Jite, vol. 3, no. 2, pp. 252-257, 2020.

[2] W. Muhamad, N. B. Kurniawan, and S. Yazid, "Smart campus features, technologies, and applications: A systematic literature review," in 2017 International Conference on Information Technology Systems and Innovation (ICITSI), 2017, pp. 384-391.

[3] A.-K. Al-Khowarizmi and F. R. Naibaho, "Smart Sensor in Water Flow Monitoring Model using Microcontroller and Raspberry PI," IJICS (International J. Informatics Comput. Sci., vol. 5, no. 1, pp. 70-75, 2021.

[4] A. P. Sembiring and V. Rolanda, "Optimizing the Fuzzy Membership Function in SAW to Detect Types of Psychopaths," vol. 1, no. 1, 2021.

[5] S.-Y. Chen, C.-Y. Chang, C.-S. Ou, and C.-T. Lien, "Detection of Insect Damage in Green Coffee Beans Using VIS-NIR Hyperspectral Imaging," Remote Sens., vol. 12, no. 15, p. $2348,2020$.

[6] K. Williamson and E. Hatzakis, "Evaluating the effect of roasting on coffee lipids using a hybrid targeted-untargeted NMR approach in combination with MRI," Food Chem., vol. 299, p. 125039, 2019.

[7] S. Darudiato, "The Pattern of The Marketing Ground Coffee Beans Using Decision Support System," in Journal of Physics: Conference Series, 2020, vol. 1500, no. 1, p. 12099.

[8] A. S. M. Muzendi, R. Oktaviani, and D. B. Hakim, “An Integration of Indonesian Market for Gree Coffee: A Review from Exported and Imported Market Outlook on the Major Exported Countries," 2019.

[9] V. Byrareddy, L. Kouadio, S. Mushtaq, and R. Stone, "Sustainable production of robusta coffee under a changing climate: A 10-year monitoring of fertilizer 
management in coffee farms in Vietnam and Indonesia," Agronomy, vol. 9, no. 9, p. 499, 2019.

[10] L. Kouadio, R. C. Deo, V. Byrareddy, J. F. Adamowski, and S. Mushtaq, “Artificial intelligence approach for the prediction of Robusta coffee yield using soil fertility properties," Comput. Electron. Agric., vol. 155, pp. 324-338, 2018.

[11] T. Sujatmiko and H. Ihsaniyati, "Implication of climate change on coffee farmers' welfare in Indonesia," in IOP Conference Series: Earth and Environmental Science, 2018, vol. 200, no. 1, p. 12054.

[12] T. Kustiasari, U. Setyoko, D. Arieni, and P. Prayitno, "Arabica Coffee Bean Quality Test With Wet Processing (Full Wash Processing) System At" Sejahtera Bersama" Farmers Group, Panti Sub-District, Jember Regency, East Java,” 2018.

[13] P. Chen, "Effects of the entropy weight on TOPSIS," Expert Syst. Appl., vol. 168, p. 114186, 2021.

[14] M. M. Salih, B. B. Zaidan, A. A. Zaidan, and M. A. Ahmed, "Survey on fuzzy TOPSIS state-of-the-art between 2007 and 2017," Comput. Oper. Res., vol. 104, pp. 207-227, 2019.

[15] K. P. Yoon and W. K. Kim, "The behavioral TOPSIS,” Expert Syst. Appl., vol. 89, pp. 266-272, 2017.

[16] P. Chen, "Effects of normalization on the entropy-based TOPSIS method," Expert Syst. Appl., vol. 136, pp. 33-41, 2019.

[17] G. Ginting, M. Fadlina, A. P. U. Siahaan, and R. Rahim, "Technical approach of TOPSIS in decision making," Int. J. Recent Trends Eng. Res, vol. 3, no. 8, pp. 58-64, 2017. 